\title{
Sehr verehrter Freund!
}

Mit Deinen Schülern haben wir, Deine äiteren und jüngeren Freunde und Collegen des In- und Auslandes, uns vereinigt, um Dir aus Anlass der Vollendung Deiner 25jährigen Thätigkeit als Professor und Vorstand der dermatologischen Klinil in Prag in den vorliegenden Bänden wissenschaftlicher Arbeiten ein Zeichen der Ehrung zu überreichen. Deine Schüler wollen durch diese Leistung aus ihrer Feder ihrem Lehrer und Meister den Dank ausdrücken; wir anderen aber wollen damit bekunden, dass $\mathrm{Du}$ durch Deine langjährige, überaus fruchtbare didaktische und wissenschaftliche Thätigkeit die volle und ungetheilte Anerkennung Deiner Fachcollegen, durch Deine gediegenen männlichen und menschlichen Eigenschaften unsere Freundschaft und Anhänglichkeit gewonnen hast.

Bestimmt einen integrirenden Bestandtheil des Archiv für Dermatólogie und Syphilis zu bilden, soll dieses Werk zugleich ein Symbol sein der grossen Autoren-Gemeinde, welche $\mathrm{Du}$ verstanden hast, um dieses, unter Deiner Leitung zu so grossem Ansehen emporgewachsene publicistische Organ unserer Fachwissenschaft zu sammeln, an dasselbe und an Deine Person zu fesseln.

In diesem dreifachen Sinne nun bieten wir diese Bände als Festgabe und bitten wir Dich, dieselben aus unserer Hand freundlich annehmen zu wollen, dazu die aus unserer aller Herzen quellenden Glückwünsche zu Deinem heutigen Jubeltage und für alle Zukunft. 
Mir aber, dem die Ehre zutheil geworden, im Namen aller Mitarbeiter dieses Werkes Dich derart zu begrüssen und zu beglückwünschen, bedeutet dieser Dein Jubeltag nicht den Abschluss eines Vierteljahrhundertes, sondern einer noch längeren Periode Deines schönen und erfolgreichen Schaffens und Wirkens. Ich gedenke dabei des Jahres I 866 - es sind 32 Jahre her - da Du, verehrter Jubilar, im Begriffe standest, von der Klinilk und Abtheilung unseres gemeinschaftlichen Lehrers und Meisters Ferdinand Hebra zu scheiden und nach Prag zu ziehen. Ein neuer Apostel der Hebra'schen Schule hast Du daselbst mit beredt lehrender Zunge, charaktervollem Ernste und reichem Können eine neue Pflanzstätte der Dermatologie gegründet, durch eigenes Talent und im eigenen Geiste entwickelt und für alle Zukunft gefestigt; dessen gedenke ich mit Freude an diesem Tage.

Ich gedenke aber auch mit grosser Genusthuung der Stunde aus jener Epoche, da Du mir, dem Jüngeren, der eben an Deine Stelle einrückte, als Abschiedsgabe Deine Freundschaft anbotest. Wir haben Beide diese Freundschaft seither gepflegt, gewahrt und gefestigt bis auf den heutigen Tag.

Als Dein Freund von damals und von heute darf ich nun mit einer Art von Recht im Namen unser Aller Dich bitten, dieses Zeichen unserer Freundschaft und Hochachtung anzunehmen, nebst unseren besten, herzlichsten Glückwünschen für Dich und die Deinen, die ich zusammenfassen möchte in die drei Worte:

ad multos annos! 